\title{
Verbal and Non-verbal Representations of Conflict in Speech
}

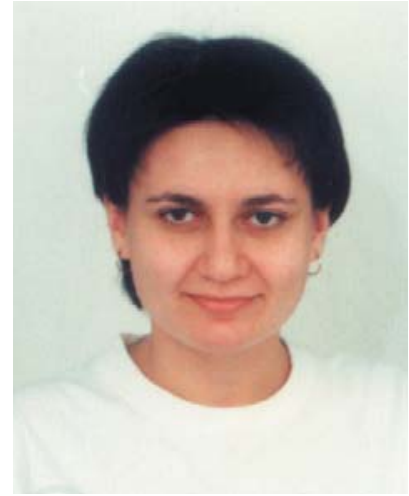

Lilit Bekaryan

$\mathbf{I}$ n everyday quarrels, public disputes, and Internet chatrooms we often resort to various means to demonstrate our negative attitude towards our interlocutors, to show our disagreement or simply to confront with them. It is interesting to note that in doing so we frequently fail to notice the huge number of verbal and non-verbal cues we deploy in speech. There is no need to say that some of them seem really inept, if not offensive in communication, and were we aware of this fact, we would definitely think twice before coming into conflict. On the other hand, we have to admit that in some conflictual situations, where the tension is quite high, nerves are overstrained and the pitch of negative emotions is extremely high, it seems very difficult to avoid using violent gestures, facial expressions and distasteful words in speech.

Conflict plays a crucial role in social interactions, and representations of conflict are an important aspect of language. The vast amount of research on conflict theory tends to show that conflict and conflictual relations have become the subject of various disciplines like social psychology, politics, e-discourse, management, etc. There has been, however, a wide range of controversies among writers over the exact definition of the term conflict. Much of the disagreement rests upon the nature, causes and the description of conflict. Thus, some psychologists consider the existence of opposing conditions to be a sufficient factor for conflict. ${ }^{1}$ Others argue that it is incumbent that a person's actions be perceived as reflecting a conflict of interests. ${ }^{2}$ Sociologists in their turn tend to be less scrupulous and state that conflict exists whenever incompatible activities occur. ${ }^{3}$

Being an inevitable part of our life, conflicts have also found their reflection in language. Thus, in some bilingual communities and countries it has become normal to speak about the so-called ethnolinguistic conflicts where languages rather than people are involved in confrontation.

Nowadays, new terms flames, to be flamed and flamers have been introduced into the word stock of the English language. Flames denote verbal attacks in electronic forms, like via e-mail or in a chatroom, and flamers are people keen on starting fights in virtual reality.

In our paper we attempt to reveal how conflictual relations between participants can find their reflection in speech and what verbal and non-verbal cues can be employed by 
them in conflictual interaction (CI). For this reason, we have conducted an analysis on conflict-based situations retrieved from modern American plays. It is worth mentioning that our analysis chiefly covers the interfamily conflict. To motivate our choice, we would like to state that family remains one of those rare spheres in society where people are relatively sincere in expressing their emotions, thoughts and feelings. Thus, while we might feel a bit uneasy to contradict our interlocutors in public places for fear of being deprived of our status in the society, power, authority, work or salary, we might not fear the aforementioned consequences when conflicting with a family member.

According to the recent statistical data, words account only for 40 percent of communication, 60 percent of communication is non-verbal. This comes to prove that while intending to convey their true emotions, thoughts and feelings, people more frequently resort to the so called non-verbal beahaviour. The term non-verbal communication can refer to facial expression, eye contact, posture, gesture and interpersonal distance or proxemics between the speakers. In support of the same theory, it is worth mentioning that there exists some disagreement among writers concerning the true meaning of non-verbal communication. Part of the disagreement stems from the fact that in most cases verbal messages are simultaneously communicated with non-verbal messages and in this way being mixed together are really difficult to be separated from each other. Such vocal aspects of speech as intonation, stress, speech rate, accent and loudness, vocal expressiveness and various non-word signs such as giggles, grunts, chuckles, hesitation markers fall into this category. Therefore, some authors tend to distinguish between direct non-verbal communication and paralanguage. ${ }^{4}$ Thus, the most important types of direct non-verbal communication distinguished by these scholars are appearance, body movement or kinesics, eye contact or oculesics, touching or haptics and proxemics (the use of personal space). As the experience shows, all five of these direct non-verbal communication forms can have a significant impact on receiving and decoding the linguistic message. Consequently they can also affect the nature and the level of conflict. Apart from this, participants might as well be influenced with paralanguage, which, as we have already mentioned, involves significant uses of the voice, as well as significant uses of graphology, or of the materials used in written discourse. Thus, the use of non-verbal cues is supposed to communicate relevant information on speakers' emotions, speech, individual differences and interpersonal relationship. Similarly, the content of individuals' thoughts, emotions and concerns can also have its impact on the rise and further development of CI. As our research shows, some verbal strategies employed by speakers might affect their interlocutors negatively, serving as an extra stimulus to conflict, whereas others might have a kind of soothing effect on them. In this respect, it is worth mentioning J.Gibb's work on communication environment or climates ${ }^{5}$, where the author distinguishes between two opposing climates for communication and describes the effects of each on the interaction and the behaviour of the participants. Accordingly, he defines the first type of communication climate as supportive, collaborative, characterized by mutual trust, sincerity and cooperation. The second type of climate Gibb calls defensive and describes it as a type of behaviour, which takes place when an individual perceives or anticipates threat in the group. 
According to Gibb, in defensive behaviour individuals are likely to produce postural, facial and verbal cues, which raise the defense level of communication. Taking this into consideration, we define the climate for CI as highly defensive. On the other hand, it seems appropriate to distinguish between various degrees of conflictual interaction respective of the intensity of conflict. It seems natural to assume, that conflicts do not start from scratch but can be the result of some hidden inner aggression, a possible consequence of an unpleasant event marked in the history of relationships of speakers, or simply an outcome of a negative disposition towards the interlocutor. It is worth mentioning, that the frequency of non-verbal cues as well as the expressive level of verbal cues can vary according to the stage and intensity of CI. The study of the factual material allows us to distinguish between three intensity levels of CI, which we with some reservations define as low, mid and high. Correspondingly, each level is marked with its own peculiarities in terms of verbal and non-verbal strategies.

Thus, when we deal with the so-called opening for conflict we deal with the low level of CI. The tension at this level is moderately low, as participants try to be relatively polite, more careful in the choice of their words and mainly express their negative disposition with the help of accusations, threats, reproaches and complaints. Thus, grammatically participants avoid imperatives and use grammatical structures made with the help of conditionals and constructions I wish + that intending them to act as softened equivalents to their indirectly expressed accusations, complaints or reproaches. Syntactically, when trying to find a fault with the other party, individuals use a special type of questions to accuse the interlocutor. In the psychological literature these questions are known as hostile or accusatory questions. In a way they are closer to rhetorical questions as, in fact, they do not need to be answered. Apparently, any answer offered to hostile questions will provoke additional accusation on the part of the speaker. Another syntactic tool deployed at this level of CI is deliberate repetition. It is generally accepted, that in conversation speakers should avoid repetition regarding it as unnecessary and time-consuming. However, frequent are the situations when speakers repeat vocabulary and syntactic structures on purpose. This is known as deliberate repetition when speakers aim for emphasis as it is in the case below.

Nancy: I want a new life. I want to go discothequing and skiing and to the beach. I want to drive through Europe on a motorcycle. All we ever do is see movies.

Allan: I write for a film magazine, they send me. Besides, I happen to like movies.

Nancy: You like movies because you're one of life's great watchers. I'm not like that. I'm a doer. I want to participate. I want to laugh. We never laugh together. (6:566)

As can be seen from this exchange, the wife indirectly accuses her husband of not providing a full and interesting life for her. For this reason, she repeats the structure $I$ 
want thrice as if intending to emphasize that her wishes do not coincide with the actions of her husband. At the same time she ignores her husband's attempts to justify himself and goes on with her charges calling her husband a watcher, whereas she, herself, is a doer. In fact, here Nancy makes her semantic selection, employing another verbal strategy and deliberately creating a kind of antonymous link between the words doer and watcher.

Individuals engaged in conflict may also use verbal conventions aiming to hurt others and exacerbate the differences between people. Stereotyping belongs to these conventions. Rather than contributing to breaking the tension, stereotypes create defensive atmosphere in communication. Stereotypes should be differentiated from generalities, which are often selected by participants at the low level of interaction. As we know, generalities occur when individuals resort to ambiguous, or exaggerated rather than concrete terms when describing feelings, events and situations. Correspondingly, generalities, as well as stereotypes prove to be very "handy" in making accusations or complaints. An example of a generality can be found in the exchange presented above where Nancy reproaches her husband for the fact that they never laugh together.

Inevitably, our analysis cannot be complete from the point of view of non-verbal cues as it seems impossible to reproduce in writing all the features of voices, movements, expressions of the participants of the conversation. Yet, to compensate for this, writers tend to influence the reader with peculiar features of typography like representing the message in bold typeface or in upper case, etc. Similarly, they describe in brackets the intonation, the tone or other vocal aspects, which affect the meaning of the utterance. The role of non-verbal cues seems to be very important at the low level of CI as here the participants being deprived of the opportunity to express their thoughts and feelings openly, subconsciously resort to various paralinguistic features to make their interlocutors realize not only what they say but also what they feel. The sample illustrated below reflects a similar case.

Cora: I wish you were home more, Rubin.

Rubin: I gotta make a livin'.

Cora: Other men make a living without traveling all over country selling harness.

Rubin: The way other men make a livin' is their business. I gotta make mine the best way I know how. I can't be no schoolmaster like your old man was when he brung you all out of here from Pennsylvania. I can't be no dentist like your brother-inlaw Morris. I was raised on a ranch and thought I'd spend my life on it. Sellin' harness is about all I'm prepared for ... as long as there's any harness to sell.

Cora: (with a trace of self-pity) I envy women who have their husbands with them all the time. I never have anyone to take me any place. I live like a widow. (7:107) 
As has already been mentioned above, much in the development of CI depends on psychological factors, like the history of relations, the age, educational background, the personality traits of the interlocutors, etc. The aforementioned exchange takes place between a wife and a husband. Meanwhile, the husband, despite his low background and upbringing, is definitely the one who is endowed with power in the house. In view of that, to soften her accusation and to sound less direct, the wife builds her speech act with the help of the construction I wish + that. The husband, however, does not make any attempts to justify himself. Meanwhile the generalities (Other men make a living without traveling all over country selling harness), (I never have anyone to take me any place) and the stereotypical assumptions employed by Cora, as well as the paralinguistic features of her utterance (with a trace of self-pity) come to prove once again that the wife does not accept her husband's explanation and sticks firmly to her opinion, though afraid to express it openly.

Unlike the low level of CI where the intensity of disjunctive emotions between participants is quite implicit, the second mid level of CI is generally marked with explicitly expressed disagreement on the part of the speakers. Therefore, this stage is mostly characterized with situations reflecting disagreement and contradicting. The semantic selection prevailing at this level comprises words showing disagreement, structures denoting the wrongness of the speaker, as well as adjectives, which negatively evaluate the speaker, thing or the person of which the speaker approves. Very often in order to express his negative attitude towards the person or the thing, the speaker can refer to them with the help of deictic markers. This choice of the speaker can be motivated by some psychological factors. Thus, subconsciously, the speaker might consider the referent of so little importance that does not find it appropriate even to mention his name in speech. Let us adduce an example:

Vandergelder: I had a talk with that artist of yours. He's a fool ...

Ermengarde: But Uncle, I love him!

Vandergelder: I tell you that you don't.

Ermengarde: But I do.

Vandergelder: And I tell you, you don't. Leave those things to me. (8:539)

It is interesting to note that mid level of CI is generally typical of those family relations, which are based on subordination, like parents - children, or uncle - niece, as it is in the sample presented above. Vandergelder does not approve of the choice of his niece referring to the young man as that artist. Moreover, he calls the young man $a$ fool and ignores Ermengarde's attempts to contradict him. As we have already mentioned, the factor of power plays not the least role in this sample and Vandergelder imposes his opinion on his niece forcing her to Leave those things to him. It is important to note that the frequency of non-verbal cues is the lowest at this level of CI. In fact, the highest 
frequency is observed at the third level of CI, the standard manifestations of which are wrangles, scuffles and rows. As our studies show, wrangles tend to prevail in discourse between children. The clue perhaps should be sought in the fact that children, usually not mature enough to motivate their actions with reason, often resort to derogatory, swear words in confrontation. Therefore, wrangles are usually nothing more than a reciprocal exchange of insults, verbal abuse and name-calling. Another verbal strategy very often employed in wrangles is sarcasm. In view of this, wrangles are very often perceived as a game by the interlocutors themselves and, in order to be terminated, need a third party intervention. In the role of the third party usually there is a person enjoying the authority and respect of the participants. Very often, the pitch of negative emotions is so high in communication that interlocutors do not consider mere words sufficient to confront with the partner. This fact may result in a scuffle, a fight of rough and noisy character. As we know, narrators are denied the opportunity to convey a complete illustration of such situations in written discourse. Therefore, they may resort to some typographic and semantic aids like excessive punctuation, underlining, upper case or describing in brackets the hostile actions taken by the interlocutors, as well as their emotional state and the pitch of their voice.

To conclude, conflicts are an inescapable part of our life, language and culture. To try to avoid them seems virtually impossible. On the other hand, being able to conflict appropriately is considered to be a kind of art, which requires enough competence and proficiency. Therefore we, individuals, have to be careful in our selection of verbal and non-verbal strategies in order to contribute to the relatively smooth and civil development of conflictual interaction.

\section{References:}

1. Brickman P. Rule Structures and Conflict Relationships. In: Social Conflict ed.by Brickman P., Lexington, MA: Heath, 1974; Lewin K. The Background of Conflict in Marriage. In: Resolving Social Conflicts: Selected Papers on Group Dynamics ed.by Lewin G.W., New York, Harper, 1948.

2. Pruitt D.G.; Rubin J.Z., Social Conflict: Escalation, Stalemate, and Settlement. New York, Random House, 1986.

3. Deutsch M. The Resolution of Conflict: Constructive and Destructive Processes. New Haven, CT, Yale University Press, 1973.

4. Borisoff D.; Victor D., Conflict Management: A Communication Skills Approach (2nd ed.). Allyn \& Bacon, 1998; Harrison R.P. Beyond Words: An Introduction to Nonverbal Communication. Englewood Cliffs, NJ: Prentice-Hall, 1974.

5. Gibb J.R. Sociopsychological Processes of Group Interaction. In: The Dynamics of Instruction Groups (Fifty-ninth Yearbook of the National Society for the Study of Education), part 11, ed.by Henry N.B., 1960. 


\section{Sources of Data:}

6. Allen W. Play it again, Sam. Best American Plays 1967-1973, Crown Publishers, Inc., New York, 1975.

7. Inge W. The Dark at the Top of the Stairs. Best American Plays 1958 - 1963, Crown Publishers, Inc., New York, 1963.

8. Wilder Th. The Matchmaker. Best American Plays 1951-1957, Crown Publishers, Inc., New York, 1987.

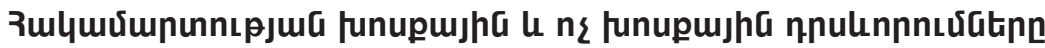 hunnnnulguviul utis}

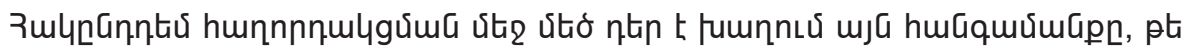

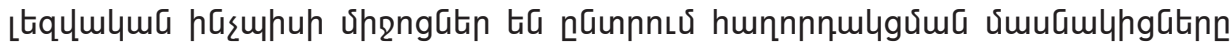

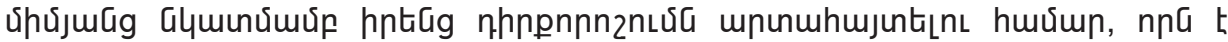

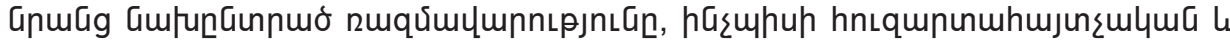

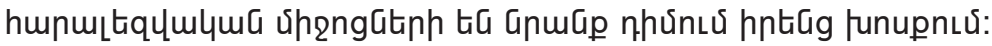

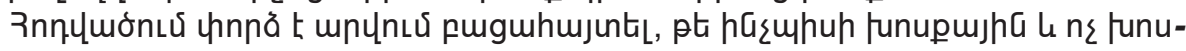

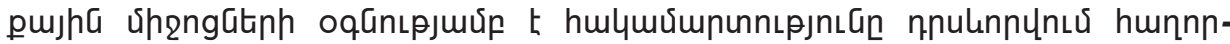

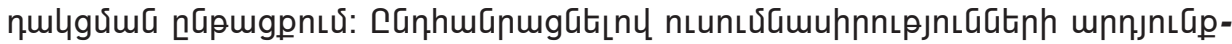

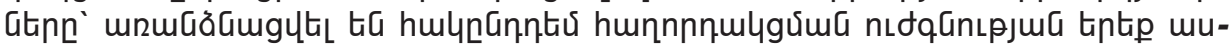
unhrua ựnu, úpgha lu nıđqha: 